\title{
EFFECT OF SHIELDING GAS PARAMETERS ON WELD METAL THERMAL PROPERTIES IN GAS METAL ARC WELDING
}

\author{
F.H. Ley ${ }^{1}$, S.W. Campbell ${ }^{1 \star}$, A.M. Galloway ${ }^{1}$ and N.A. McPherson ${ }^{2}$ \\ ${ }^{1}$ Dept. of Mechanical \& Aerospace Engineering, University of Strathclyde, Glasgow, UK \\ ${ }^{2}$ BAE Systems Surface Ships Limited, 1048 Govan Road, Glasgow, UK \\ *stuart.campbell@strath.ac.uk
}

\begin{abstract}
This study considered the effect of shielding gas parameters (composition, supply method and flow rate) on the post weld thermal properties (thermal expansion, specific heat capacity, thermal diffusivity and thermal conductivity) of the weld metal in gas metal arc welding. This is of importance as the thermal properties influences the temperature distribution and therefore the residual stresses and distortion present within the final structure.
\end{abstract}

Due to the lack of accurate thermal data, computational modelling techniques (such as FEA, CFD, etc.) used for modelling the welding process generally make assumptions regarding the material thermal properties, and it is often the case that the parent material thermal properties are extended to the weld metal, introducing errors to the simulation.

It was determined that the weld metal posses considerably different thermal properties to the $\mathrm{DH} 36$ grade steel parent material, and that the shielding gas parameters significantly alter key thermal properties of the solidified weld metal. A lower shielding gas flow rate exhibited beneficial properties including a lower thermal expansion, and higher specific heat capacity and thermal conductivity than a higher shielding gas flow rate. 


\section{Keywords}

GMAW; weld metal thermal properties; thermal expansion; specific heat; thermal diffusivity; thermal conductivity

\section{List of Symbols}

$\beta \quad$ Thermal expansion coefficient (1/K)

$R \quad$ Cooling rate $(\mathrm{K} / \mathrm{s})$

$k \quad$ Thermal conductivity $\left(\mathrm{W} / \mathrm{mm}^{*} \mathrm{~K}\right)$

$\rho \quad$ Density $\left(\mathrm{kg} / \mathrm{m}^{3}\right)$

$C_{p} \quad$ Specific heat capacity $\left(\mathrm{J} / \mathrm{g}^{*} \mathrm{~K}\right)$

$t \quad$ Plate thickness $(\mathrm{mm})$

$H_{\text {net }} \quad$ Net heat input $(\mathrm{J} / \mathrm{mm})$

$T_{c} \quad$ Cooling rate at temperature of interest $(\mathrm{K})$

$T_{0} \quad$ Initial temperature $(\mathrm{K})$

$S \quad$ Solidification time (s)

$L \quad$ Latent heat of fusion $\left(\mathrm{J} / \mathrm{mm}^{3}\right)$

$T_{m} \quad$ Melting temperature $(\mathrm{K})$

\section{Introduction}

Since its initial development, gas metal arc welding (GMAW) has grown to become one of the most commonly used joining processes of metals across industry today, including shipbuilding and construction.

Although the alternating shielding gas process was first suggested in 1967 [1], its uptake was slow and the majority of the process benefits have been established 
within the last decade. The process involves the discreet periodic supply of two different shielding gases to the welding region in order to take advantage of the beneficial properties of each shielding gas.

The alternating shielding gas process has been applied as a shielding gas supply method in arc welding processes; particularly for aluminium alloys $[2,3,4,5,6,7,8]$, carbon $[8,9,10]$ and stainless $[3,11,12]$ steels, and narrow gap welding [13]. This shielding gas supply method has resulted in a number primary benefits being achieved, as well as several interrelated benefits when compared to conventional supply methods including a reduced edge preparation requirement, an increase in productivity, which has associated benefits including a reduction in weld induced distortion, and electrical energy and shielding gas consumption, improvements in mechanical and microstructural properties, and improvements in post weld efficiency including increased accuracy of manufacture, a reduction in rework and fewer rejected components.

The alternating shielding gas process benefits achieved have been based upon three independent theoretical phenomena [3]: variation in weld pool fluidity, arc pressure variation and arc pressure peaking, which create fluid flow vectors opposite in direction for argon and helium.

Recently, transient arc pressure measurement whilst using argon, helium, alternating shielding gases and pulsed GTAW have been conducted [14], from which various forces acting on the liquid weld metal have been calculated [15]. The arc pressure for alternating shielding gases was found to be considerably higher ( $25 \%)$ than the steady-state values for argon and helium due to a pressure impulse at weld initiation, and was considerably different from the previous theoretical assumptions stated 
previously due to the short period of time each gas is supplied. It was also stated that based on the forces acting on the liquid weld metal, the flow vectors for helium are opposite in direction to that produced by argon, creating a dynamic action within the weld pool when using alternating shielding gases.

The correct shielding gas flow rate is essential for providing adequate protection to the weld metal during the heating, liquation and solidification stages. It is known that too low a flow rate can lead to inadequate coverage of the arc area, which often leads to porosity and excess spatter development. Conversely, too high a flow rate can result in poor penetration [16] and/or porosity due to turbulence in the gas column. In the case of the latter, the turbulence effect results in atmospheric gases being drawn into the arc [17], which promotes the formation of entrapped gas (porosity) during the solidification phase. Hence, there is an optimum flow rate for weld shielding gases, but this is difficult to define and is often decided on the basis of preference or experience.

Studies have therefore been conducted $[18,19,20,21,22]$ with the aim of improving the efficiency of the GMAW process by reducing the shielding gas consumption. Campbell et al. [18] investigated the use of gas saving devices to restrict the allowable shielding gas flow rate, and determined that the flow rate could be reduced to $6 \mathrm{~L} / \mathrm{min}$ without detriment to weld quality in laboratory conditions. In the industrial workplace however, drafts present a significant threat to weld quality, potentially removing the protection provided by the shielding gas. Several techniques have been applied to determine safe working conditions in which the shielding gas flow rate can be reduced; Shadowgraphy [19] was used to experimentally visualise the shielding gas column, whilst computational fluid dynamics [20,21] and artificial neural networks [22] have been used to simulate the shielding gas column and predict the 
weld quality respectively for a range of shielding gas flow rates and cross draft velocities.

Distortion is a problem that occurs in many manufacturing process and is particularly prevalent in the shipbuilding industry due to the non-uniform expansion and contraction cycles present in the arc welding processes implemented. During the welding process, the workpiece is locally heated by what is essentially a point source. The temperature distributions along its length and across its width are nonuniform and change as the process progresses [23]. As a result, residual stresses are introduced to the surrounding material, resulting in distortion in the final welded structures; a common problem associated with any welding process [24]. Although it has been shown that there is a critical limit to the angular distortion due to the welding process [25], the magnitude of the weld-induced distortion is primarily related to the specific thermal energy input of the welding process [26].

Distortion is an increasing problem when structures are constructed using a unit assembly process, and consequently distortion can be detrimental when the welded sub-structures have to be aligned and joined together. For example, fillet welds are commonly used in the shipbuilding industry to attach stiffener bars to larger flat sections to improve the rigidity of the structure. However, fillet welded configurations generally lead to out-of-plane distortion, which is particularly troublesome when joining the previously mentioned flat sections to one another to form part of a larger structure $[27,28]$.

The effort required to rectify the distortion from the plate is highly resource intensive, and it is therefore beneficial to eliminate as much distortion at source as possible. This is largely achievable through good practices mainly related to reducing the heat 
going into the plates and the concentration of heat in specific areas. For this reason, a reduction in heat input is a primary manufacturing goal.

Computational modelling has become increasingly popular over the past few decades for the prediction of various aspects of the welding process. Extensive studies have been conducted in areas fundamental to the final structure, namely residual stresses in the weld region [29,30,31], weld induced distortion [25,26,30,31] and the solidified weld geometry $[10,31]$.

Zhu and Chao [24] used a computational model to investigate the effect that temperature dependant thermal properties have on the temperature field produced during the GMAW process. This study modelled the temperature fields using room temperature, averaged linear, and temperature variant values for specific heat capacity $(C p)$ and thermal conductivity $(k)$, and concluded that temperature variant thermal properties produced the most accurate results.

Zhu and Chao [24] also describe in detail previous authors that have conducted studies into temperature dependant material properties and concluded that the unavailable material property data at higher temperatures has negligible effect on the residual stresses and distortion. However, these studies did not perform computational simulations to compare their assumptions with accurate thermal property data, nor did they differentiate between the thermal properties of the parent plate and the weld metal, thus the conclusions that they reached are unfounded.

Due to a lack of experimental data, the difference in thermal properties between the parent plate and weld metal are neglected, and many computational modelling simulations generally make the assumption that the thermal properties of the weld metal [30], i.e. specific heat capacity, coefficient of thermal expansion, thermal 
conductivity and thermal diffusivity, are the same as those for the parent plate. However, particularly in GMAW, the filler material generally has a different chemical composition and mechanical property data to that of the parent material. In addition, Mollicone et al. [26] and Camilleri et al. [31] presented dilatometer data, which indicated that the parent plate and filler material posses different coefficient of thermal expansions and, from this, it can therefore be inferred that the other thermal properties will also differ. Thus the accuracy of the simulation is only as accurate as the material property data supplied.

The present study has therefore been undertaken to obtain various thermal property data including the linear thermal expansion coefficient, specific heat capacity, thermal conductivity and thermal diffusivity, within the weld material itself and for the parent plate. In doing so generating thermal property data for a range of shielding gas configurations and flow rates, which will help improve the accuracy of future computational simulations. An explanation as to why different shielding gases affect the weld-induced distortion, and various mechanical properties is also discussed.

\section{Experimental Procedure}

A series of bead on plate welds were performed using an automatic welding rig that while holding the test plate rigid, moved it beneath a stationary welding torch at a constant travel speed of $3.2 \mathrm{~mm} / \mathrm{s}$. Trials were performed on $150 \times 500 \times 8 \mathrm{~mm}$

DH36 steel plate using $1.2 \mathrm{~mm}$ diameter Nittetsu SF-1A filler wire and a constant standoff distance of $10 \mathrm{~mm}$. Nominal weld parameters of $210 \mathrm{~A}$ and $24.7 \mathrm{~V}$ were used throughout.

Two shielding gas supplies were used throughout, premixed $80 \% \mathrm{Ar} / 20 \% \mathrm{CO}_{2}$ and pure He. The weld configurations analysed are shown in Table 1. 


\begin{tabular}{|l|l|l|}
\hline Shielding Gas & Gas Delivery Method & Gas Flow Rate (L/min) \\
\hline $\mathrm{Ar} / \mathrm{CO}_{2}$ & Constant & $5,10,15$ \\
\hline $\mathrm{He}$ & Constant & $5,10,15$ \\
\hline $\begin{array}{l}\mathrm{Ar} / \mathrm{CO}_{2} \\
\mathrm{He}\end{array}$ & Alternating @ 2,4,6,8 Hz & $5,10,15$ \\
\hline
\end{tabular}

Table 1: Weld Configurations

All thermal analysis specimens were machined from the weld metal and, for comparison purposes, samples were also prepared from the parent material for comparison. Specimens were prepared as follows; $4 \mathrm{~mm}$ diameter cylindrical rods, $25.5 \mathrm{~mm}$ length samples were taken in the longitudinal weld direction for dilatometry, $4 \mathrm{~mm}$ diameter discs, $2 \mathrm{~mm}$ in height, for simultaneous thermal analysis (STA), and $12.5 \mathrm{~mm}$ discs, $3 \mathrm{~mm}$ height for laser flash analysis (LFA).

\section{Results and Discussion}

\section{Linear Thermal Expansion Coefficient}

The thermal expansion coefficient $(\beta)$ for each of the specimens was evaluated through the use of a push-rod dilatometer (NETSZCH DIL 402C $®$ ) according to ASTM E228. A linear variable differential transformer allows the displacement to be measured by means of a voltage difference, which can then be converted to a displacement signal. As the temperature is closely recorded by a thermocouple within the chamber, the information can provide the linear thermal expansion characteristics of the specimen. The change in length of the specimen with respect to temperature allowed for $\beta$ to be calculated; linear thermal expansion coefficient data was measured from a $1200^{\circ} \mathrm{C}$ reference temperature to $300^{\circ} \mathrm{C}$. 


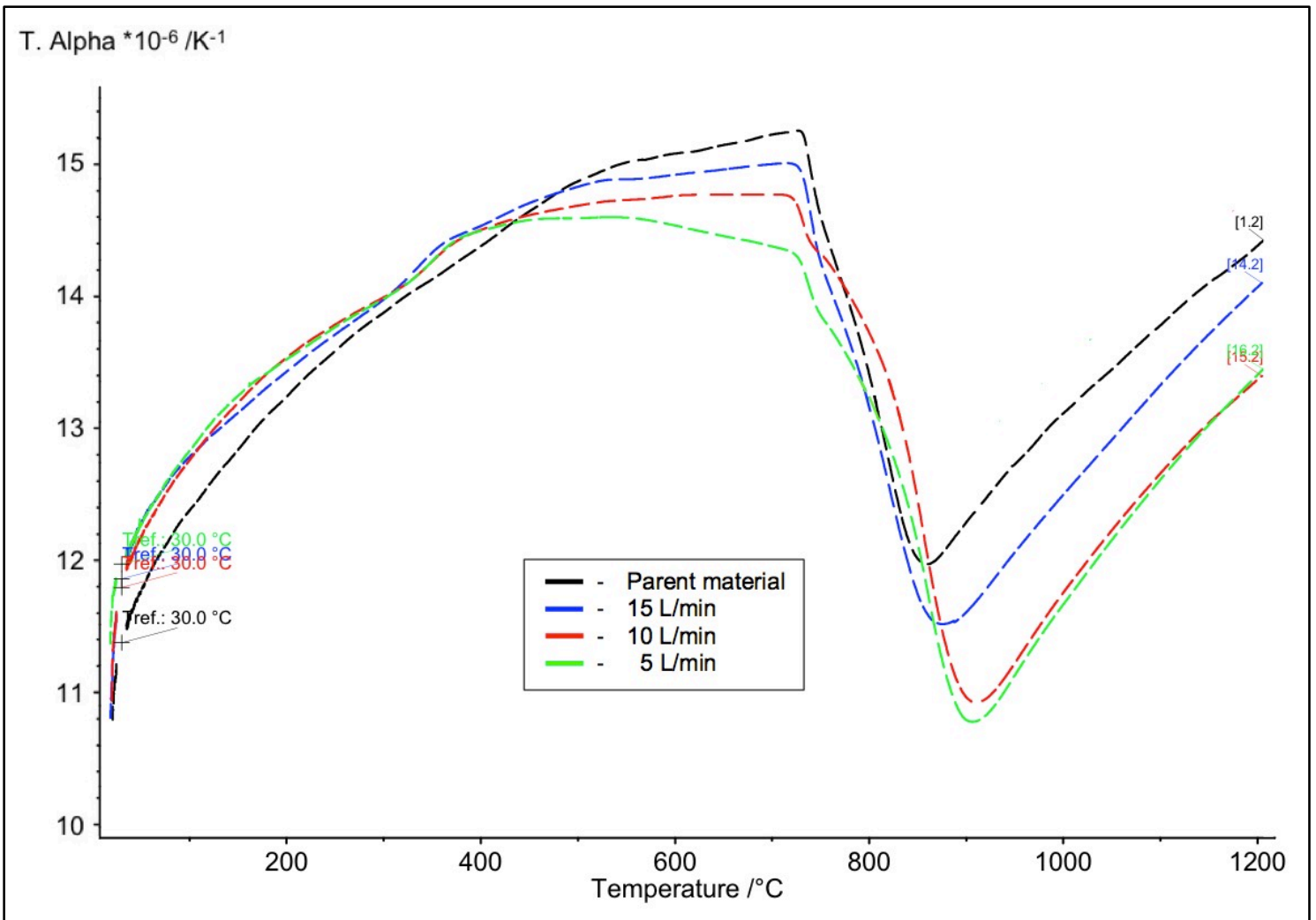

Figure 1: Thermal Expansion Coefficient vs. Temperature at an alternating frequency

$$
\text { of } 8 \mathrm{~Hz}
$$

Figure 1 shows thermal expansion coefficient, $\beta$ vs. temperature for alternating shielding gases at a frequency of $8 \mathrm{~Hz}$ and comparing the various flow rates, and also shows the characteristic phase change at approximately $700 \mathrm{C}$. As expected, there is a degree of variation in the thermal property data at a temperature around the phase change. The important aspect that is being emphasised is that there is a definite difference in the thermal properties as a function of the shielding gas parameters.

The technical alpha curve gives the average expansion coefficient over the temperature range. The parent material consistently exhibited the highest linear thermal expansion coefficient for temperatures above approximately $400 \mathrm{C}$, which is in line with other studies $[26,31]$. As can be seen, when comparing the weld metal 
samples, the $15 \mathrm{~L} / \mathrm{min}$ flow rate exhibits the greatest linear thermal expansion coefficient over the temperature range of the experiment. A similar trend was found for each shielding gas configuration, i.e. the lower the shielding gas flow rate, the lower the $\beta$ of the weld metal. This is in contrast to published experimental distortion data [18], however, the study suggested that reducing the shielding gas flow rate increased the heat transfer efficient factor. Therefore, the current study is of the viewpoint that a lower shielding gas flow rate, with the same heat input, would result in a lesser degree of distortion.

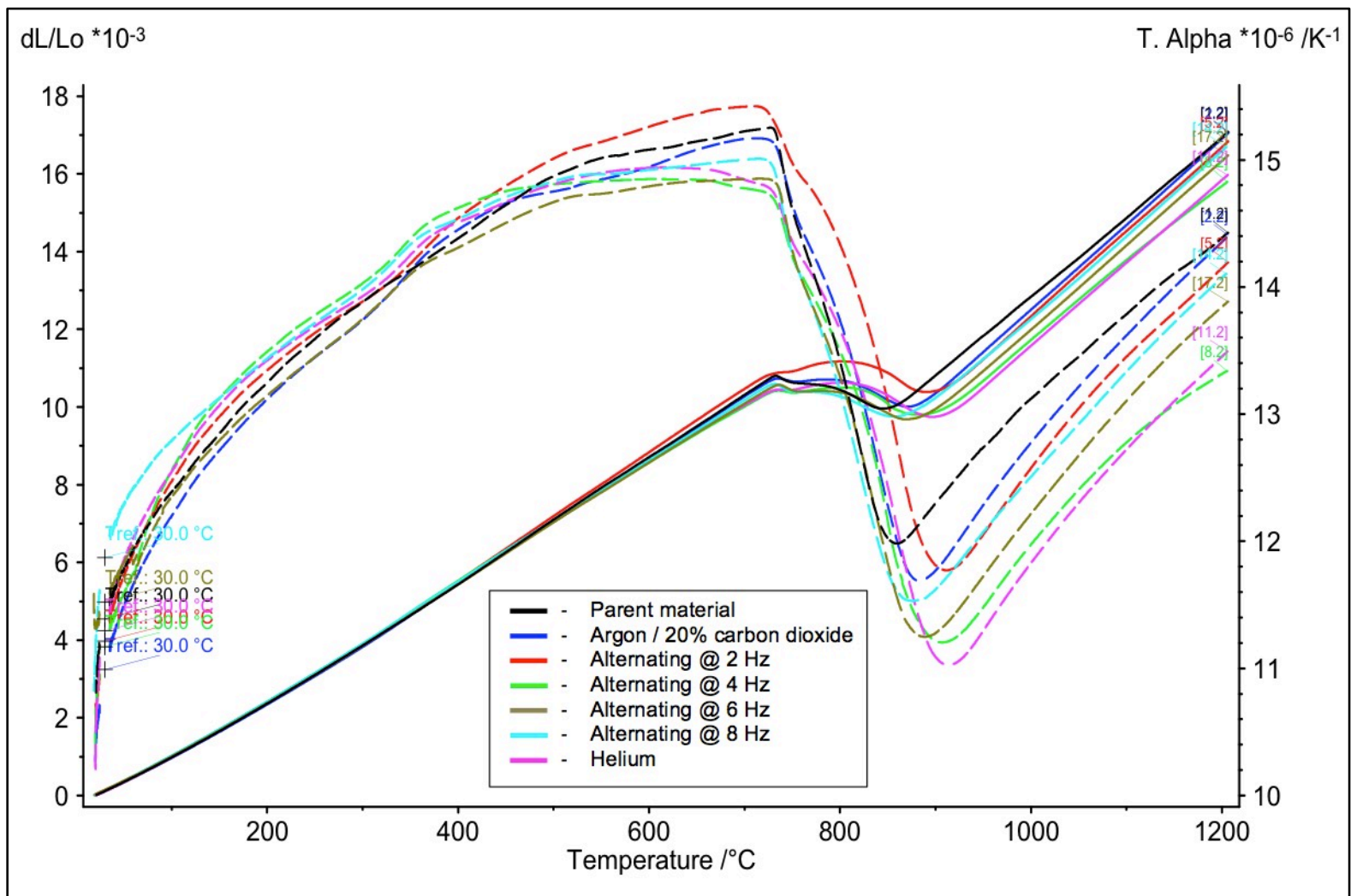

Figure 2: Thermal Expansion Coefficient and Change in Length vs. Temperature at $10 \mathrm{~L} / \mathrm{min}$

When comparing the linear expansion coefficient for the weld metal for the same shielding gas flow rate, Figure 2, it can be noted that the $\mathrm{Ar} / \mathrm{CO}_{2}$ maintained a higher thermal expansion coefficient than the He configuration, this was the case each of 
the three shielding gas flow rates evaluated. However, no trend could be found within the alternating shielding gas configurations used, other than they were generally between the upper $\mathrm{Ar} / \mathrm{CO}_{2}$ value and the lower $\mathrm{He}$ value. The use of alternating shielding gases has previously been shown to reduce the level of weld induced distortion when compared to a conventional shielding gas supply $[4,9,11]$, and is therefore in agreement with the present study.

As the thermal expansion coefficient changes in a material, its expansion-contraction due to various temperatures is understandably affected. Due to the rapid, nonequilibrium heating/melting of the weld metal, coupled with the constraint imposed by the surrounding plate, the filler material does not have sufficient time to expand. Upon cooling of the weld metal, heat is conducted to the adjacent plate, resulting in contraction of the weld metal and expansion of the surrounding material. Once thermal equilibrium between the weld metal and the adjacent plate occurs, further cooling will take place by convection and approximately uniform contraction will occur. Thus the majority of distortion is introduced to the structure during the cooling phase. This is evident within the welding process where this expansion-contraction effect is highly significant as it has a direct impact upon the residual stresses present within the structure following cooling. It was found that at higher shielding gas flow rates, the thermal expansion coefficients were higher throughout the temperature range. This will therefore lead to a greater volumetric expansion contraction within the weld metal, which will in turn lead to greater residual stress within the structure.

Therefore, when considering the thermal expansion of the weld metal, theoretically the use of a lower flow rate proves beneficial for reducing the distortion present within the final structure. However, Campbell et al. [18] found that a lower shielding 
gas flow rate resulted in greater distortion, although this was attributed to a greater thermal efficiency due to an increase in weld penetration.

\section{Specific Heat Capacity}

The specific heat capacity (Cp) was analysed by STA using a NETSZCH STA 449 F1 Jupiter $®$ according to ASTM E1269. Specimens were placed in a platinum sample pan with an alumina liner with lid. Nitrogen was used to provide a protective atmosphere and heating was conducted from a reference temperature of $25^{\circ} \mathrm{C}$ to $1200^{\circ} \mathrm{C}$.

Through comparison of the Cp vs. temperature data generated, the effects that the shielding gas supply configuration, and that of the various flow rates, could be analysed.

Figure 3 shows Cp vs. temperature for alternating shielding gases at a frequency of $2 \mathrm{~Hz}$ and comparing the various flow rates. It was found that the $\mathrm{Cp}$ of the parent material was considerably higher than any of the weld metal configurations, whilst the $5 \mathrm{~L} / \mathrm{min}$ shielding gas flow rate exhibits the greatest $\mathrm{Cp}$, followed by $10 \mathrm{~L} / \mathrm{min}$ and 15 L/min respectively. A similar trend was found for each shielding gas configuration, i.e. the lower the shielding gas flow rate, the greater the $\mathrm{Cp}$ of the weld metal. 


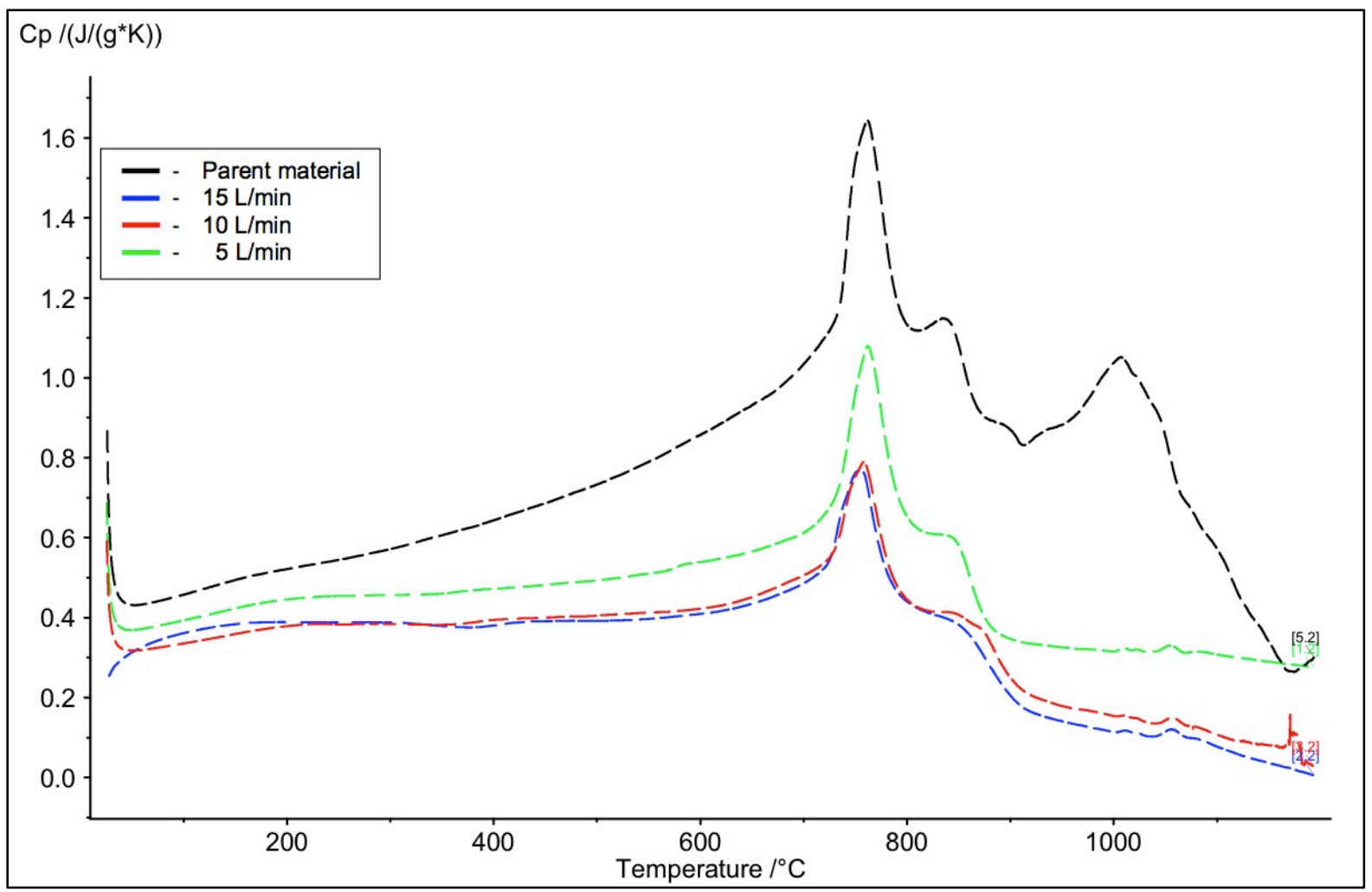

Figure 3: Specific Heat Capacity vs. Temperature at $2 \mathrm{~Hz}$

The $\mathrm{Cp}$ influences various parameters of the welding process; the cooling rate along the centreline of thin plate and the solidification rate of the weld metal are given by equation 1 and 2 respectively [32]. These parameters are known to have a significant affect on the metallurgical structure, properties, response to heat treatment, and soundness of the material [32].

$$
\begin{aligned}
& R=2 \pi k \rho C_{p}\left(\frac{t}{H_{n e t}}\right)^{2}+\left(T_{c}-T_{0}\right)^{2} \\
& S=\frac{L H_{n e t}}{2 \pi k \rho C_{p}\left(T_{m}-T_{0}\right)^{2}}
\end{aligned}
$$

As can be noted, a larger weld metal $\mathrm{Cp}$ value will result in a faster cooling rate and quicker solidification time than a lower $\mathrm{Cp}$, with the potential for bainitic or martensitic grain structures in the weld metal, and a more refined microstructure in the heat affected zone. 


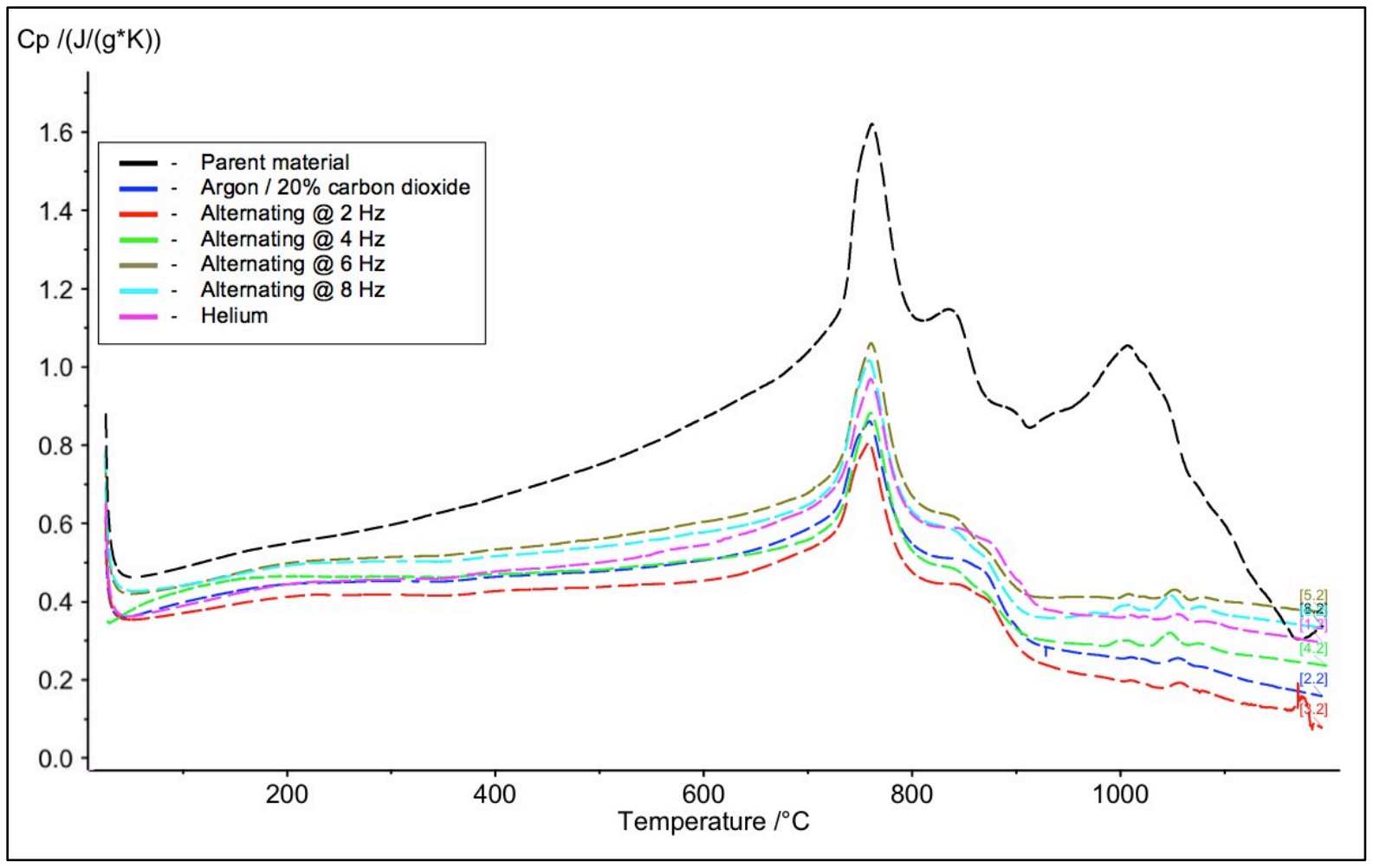

Figure 4: Specific Heat Capacity vs. Temperature at $10 \mathrm{~L} / \mathrm{min}$

Figure 4 shows $\mathrm{Cp}$ for each shielding gas configuration at a shielding gas flow rate of $10 \mathrm{~L} / \mathrm{min}$. It was found that the He configuration exhibited a consistently higher $\mathrm{Cp}$ than the $\mathrm{Ar} / \mathrm{CO}_{2}$ configuration, and although there was no trend for the alternating frequencies, they generally come within the upper and lower limits imposed by the constant flow shielding gases. Campbell et al. [9] found that alternating shielding gases produced a more refined microstructure in the weld metal than $\mathrm{Ar} / \mathrm{CO}_{2}$, which was attributed to a faster cooling rate for alternating shielding gases not permitting as much time for grain growth as conventional $\mathrm{Ar} / \mathrm{CO}_{2}$.

\section{Laser Flash Analysis}

LFA was carried out using a NETSZCH LFA 427@in order to determine both the thermal diffusivity and thermal conductivity of the specimens. The specific heat data gathered from the STA was imported to the LFA to increase the accuracy of the 
analysis, in accordance with ASTM E1461. The specimen was mounted in a furnace via a carrier system, and heated. At predetermined temperature steps $\left(100^{\circ} \mathrm{C}\right)$ a high intensity short duration radiant energy laser pulse is fired at the samples top surface, and the time taken for a temperature increase to be measured on the opposite surface recorded. The thermal diffusivity can be calculated through this information and is an indication of the materials ability to conduct thermal energy relative to its ability to store thermal energy. As with the other thermal analysis, LFA was performed from a reference temperature of $25^{\circ} \mathrm{C}$ to $1200^{\circ} \mathrm{C}$.

Figure 5 , shows the three shielding gas flow rates at a frequency of $4 \mathrm{~Hz}$.

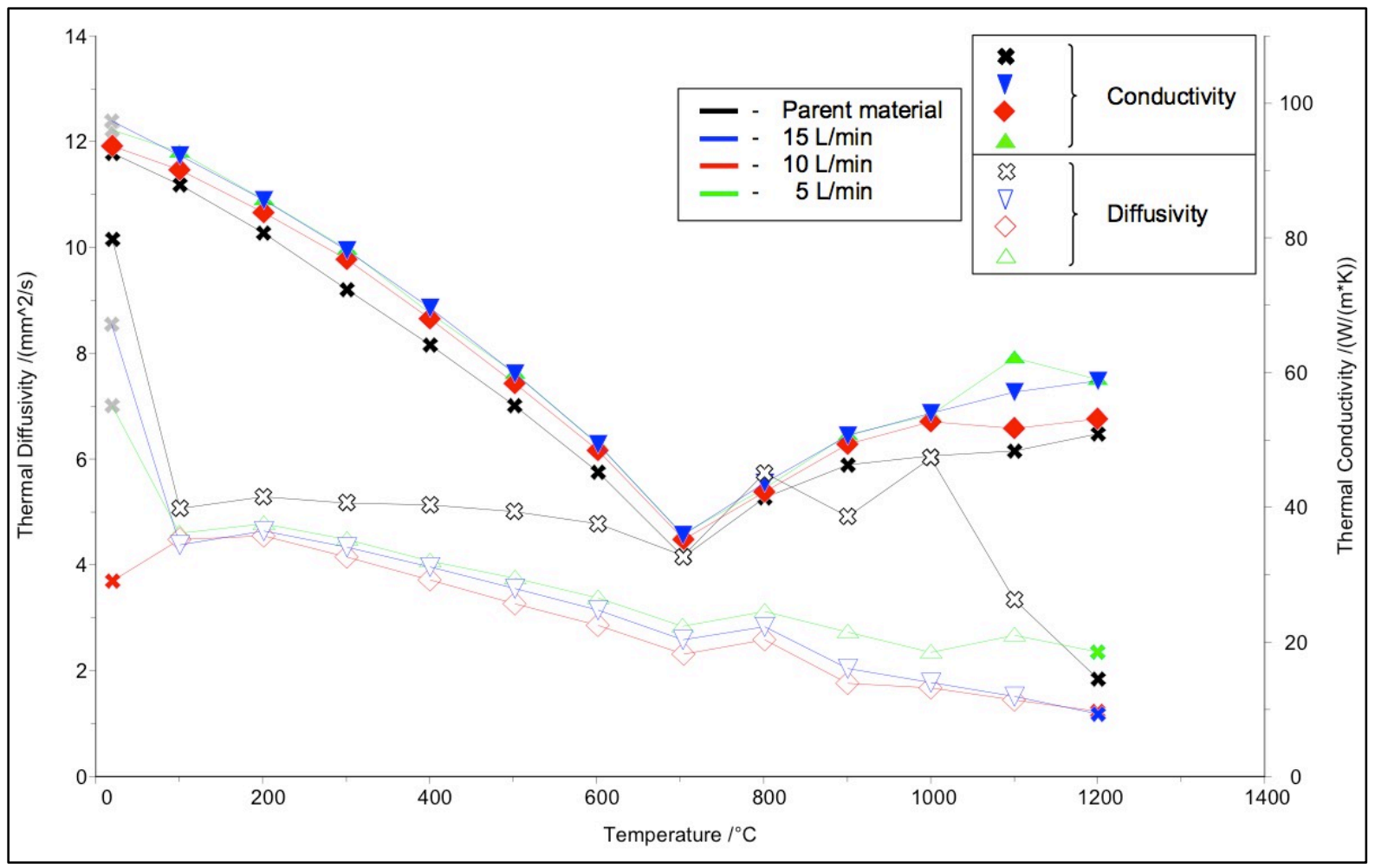

Figure 5: Thermal Conductivity and Diffusivity vs. Temperature at $4 \mathrm{~Hz}$ As can be seen in Figure 5 , the $5 \mathrm{~L} / \mathrm{min}$ input gas configuration shows a higher thermal conductivity than 10 and $15 \mathrm{~L} / \mathrm{min}$ cases as the temperature is increased. As with the other analysis conducted, a similar trend was found for each shielding 
gas configuration, i.e. the lower the shielding gas flow rate, the greater the thermal conductivity of the weld metal.

It can also be noted that the thermal diffusivity across the three welds was almost the same with no configuration being significantly higher or lower. Again this trend was apparent across all the sets of welds where input flow rate was compared within the same gas configurations.

For comparison of varying gas configuration at a constant shielding gas flow rate of $10 \mathrm{~L} / \mathrm{min}$, the thermal conductivity is shown in Figure 6.

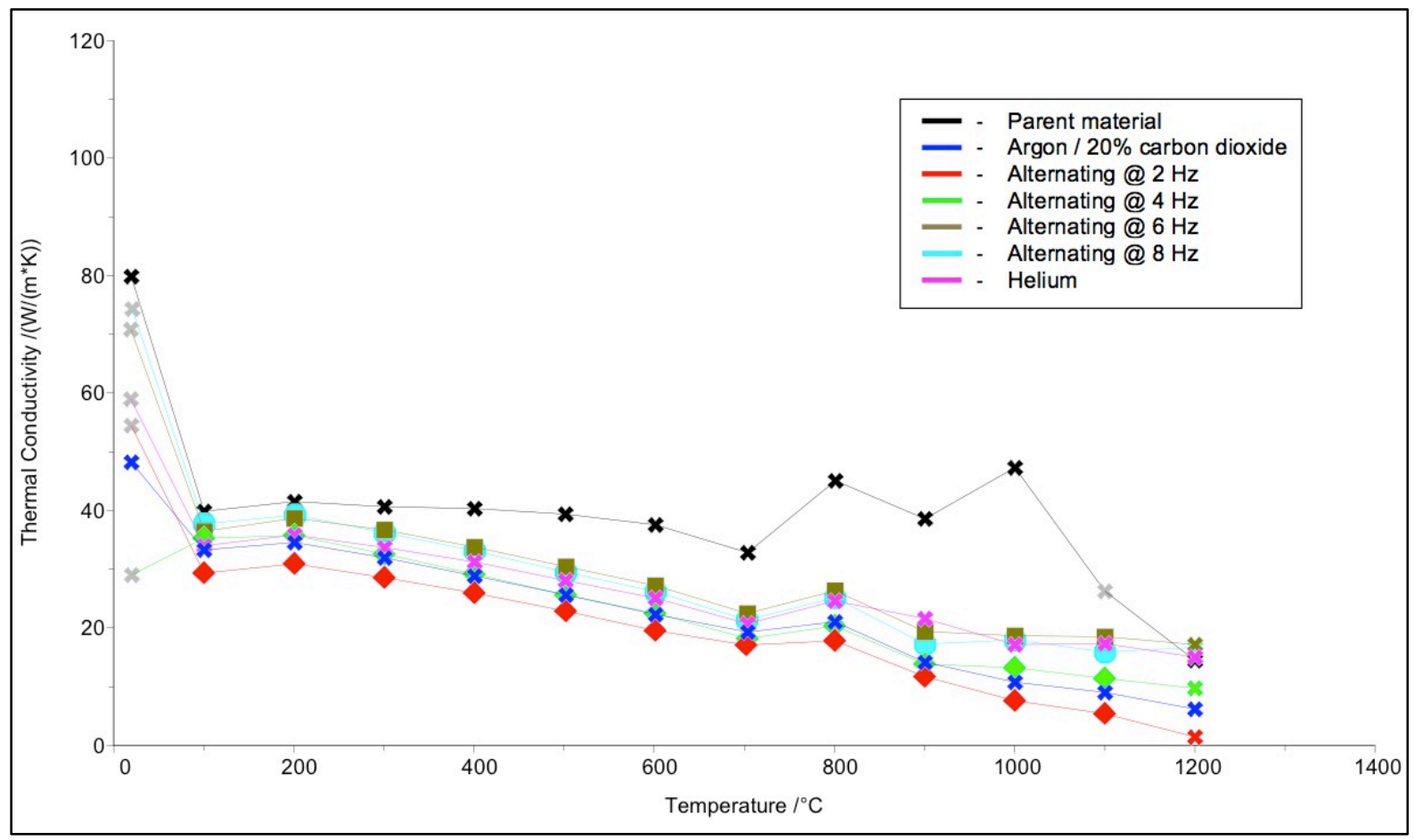

Figure 6: Thermal Conductivity vs. temperature of samples at $10 \mathrm{~L} / \mathrm{min}$

As thermal conductivity increases, the elevated temperature in the liquid weld metal will change more quickly as the heat can be transferred faster to the surrounding material, resulting in an increased temperature away from the weld [29]. This was found in practice by Campbell et al. [18] who reported that a lower shielding gas flow 
rate resulted in an increase in temperature $10 \mathrm{~mm}$ from the weld centreline. This increase in heat flow will result in the heat flux during the weld being diffused in a shorter space of time. It is suggested that as a result of the temperature flux caused by the welding process being dissipated faster to the surrounding plate, the weld metal and surrounding plate will reach thermal equilibrium quicker and as a result the residual stresses will be lower as the thermal conductivity is increased. Lower residual stresses are expected to occur as the plate will cool more evenly, and there will be a smaller temperature gradient across the structure.

As can be seen in Figure 5, the thermal diffusivity $(\alpha)$ remains constant even with varying thermal conductivity. This can be explained through equation 3 for thermal diffusivity:

$$
\alpha=\frac{k}{\rho C_{p}}
$$

As discussed previously, the specific heat capacity, was found to follow the same trend as that of the thermal conductivity, i.e. as the flow rate is increased both $\mathrm{Cp}$ and $\mathrm{k}$ decrease. Although this was not at the same rate, it explains why the thermal diffusivity across all data sets remains almost constant when varying the input parameters.

\section{Conclusions}

Fundamental variables such as the shielding gas flow rate or configuration affects the temperature dependant thermal properties of the weld metal. Therefore, assumptions made in computational modelling that the thermal properties of the weld 
metal are the same as those for the parent plate introduces unnecessary error to the simulation.

This study has highlighted the influence that the shielding gas parameters have on the weld metal thermal properties and therefore each set of welding parameters will exhibit unique aspects. Therefore, the accuracy of temperature field simulations, and consequently residual stress and distortion analysis can be improved through the use of temperature dependant thermal properties for the parent plate and weld metal.

It has been determined that the shielding gas parameters have a significant effect on the thermal properties of the solidified weld. A lower shielding gas flow rate, and a shielding gas composition containing helium, were found to reduce the linear thermal expansion coefficient, increase the specific heat capacity and increase the thermal conductivity, whilst the thermal diffusivity was independent of the shielding gas parameters. Thus, it can be inferred that, for the same level of heat input to the workpiece, a lower shielding gas flow rate and a shielding gas composition containing helium will result in less weld-induced distortion as a result of lower degree of weld metal contraction, and quicker dissipation of the heat to the surrounding plate, resulting in quicker thermal equilibrium with the surrounding material. In addition, the higher $\mathrm{Cp}$ associated with these configurations would result in a faster weld metal cooling rate, producing a finer microstructure.

There were no real trends in the data produced when varying the frequency of alternating shielding gases, although the results were generally found to be within the upper and lower limits imposed by $\mathrm{Ar} / \mathrm{CO}_{2}$ and $\mathrm{He}$. 


\section{Acknowledgements}

The authors would like to acknowledge the funding provided by BAE Systems Surface Ships Limited, which has made this research possible.

\section{References}

[1] Cunningham, J. W., 'Pulsed welding and cutting by variation of composition of shielding gas', US Patent no. 3,484,575, 1969.

[2] Barabokhin, N. S., Bushuev, Y. G., Shulgina, E.V., Kazakov, V. A., Silis, V. E.,

Dudryashov, O. N., Novikov, O. N. and Makarov, N. V., 'Technological special features of welding 1460 high-strength aluminium alloy', Welding International, Vol. 14, No. 6, pp. 468-470, 2000.

[3] Chang, Y. H., 'Improve GMAW and GTAW with alternating shielding gases', Welding Journal, Vol. 85, No. 2, pp. 41-43, 2006.

[4] Campbell, S. W., Galloway, A. M., McPherson, N. A. and Gillies, A., 'Evaluation of gas metal arc welding with alternating shielding gases for use on AA6082T6', Proceedings of the Institution of Mechanical Engineers, Part B: Journal of Engineering Manufacture, Vol. 226, No. 6, pp. 992-1000, 2012.

[5] Kang, B. Y., Prasad, Y. K. D. V., Kang, M. J., Kim, H. J. and Kim, I. S., 'Characteristics of alternate supply of shielding gases in aluminium GMA welding', Journal of Materials Processing Technology, Vol. 209, No. 10, pp. 4716-4721, 2009.

[6] Novikov, O. M., Persidskii, A. S., Rad'ko, E. P., Baranovskii, A. V. and Khasyanov, B. A., 'Effect of the composition of the shielding gas on the properties of 
arc welded joints in aluminium alloys', Welding International, Vol. 26, No. 5, pp. 384387, 2012.

[7] Novikov, O. M., Persidskii, A. S., Rad'ko, E. P., Baranovskii, A. V. and Khasyanov, B. A., 'Effect of changes in the composition of the gas shielding medium on the properties of arc welded joints in aluminium alloys', Welding International, Vol. 27, No. 3, pp. 222-225, 2013.

[8] Tazetdinov, R. G., Novikov, O. M., Persidskii, A. S., Khasyanov, B. A., Ivanov, E. N. and Plaksina, L. T., 'Arc welding in shielding gases with alternate pulsed supply of dissimilar gases', Welding International, Vol. 27, No. 4, 2013.

[9] Campbell, S. W., Galloway, A. M. and McPherson, N. A., 'Techno-economic evaluation on the effects of alternating shielding gases for advanced joining processes', Proceedings of the Institution of Mechanical Engineers, Part B: Journal of Engineering Manufacture, Vol. 225, No. 10, pp. 1863-1872, 2011.

[10] Campbell, S. W., Galloway, A. M. and McPherson, N. A., 'Artificial neural network prediction of weld geometry performed using GMAW with alternating shielding gases', Welding Journal, Vol. 91, No. 6, pp. 174s-181s, 2012.

[11] Kang, B. Y., Prasad, Y. K. D. V., Kang, M. J., Kim, H. J. and Kim, I. S., 'The effect of alternate supply of shielding gases in austenite stainless steel GTA welding', Journal of Materials Processing Technology, Vol. 209, No. 10, pp. 47224727, 2009.

[12] Traidia, A. and Roger, F., 'A computational investigation of different helium supplying methods for the improvement of GTA welding', Journal of Materials Processing Technology, Vol. 211, No. 9, pp. 1553-1562, 2011. 
[13] Nakamura, T., Hiraoka, K., Takahishi, M. and Sasaki, T., 'Gas metal arc welding with periodic control of shielding gas composition', Science and Technology of Welding and Joining, Vol. 10, No. 2, pp. 131-138, 2005.

[14] Campbell, S. W., Galloway, A. M. and McPherson, N. A., 'Arc pressure and weld metal fluid flow while using alternating shielding gases. Part 1: arc pressure measurement', Science and Technology of Welding and Joining, Vol. 18, No. 7, pp. 591-596, 2013.

[15] Campbell, S. W., Galloway, A. M. and McPherson, N. A., 'Arc pressure and fluid flow during alternating shielding gases. Part 2: arc force determination', Science and Technology of Welding and Joining, Vol. 18, No. 7, pp. 597-602, 2013.

[16] Loxton Industries, 'New welding gas innovation', Australasian Welding Journal, Vol. 55, No. 1, pp. 10-11, 2010.

[17] Uttrachi, G. D., 'GMAW shielding gas flow control systems', Welding Journal, Vol. 86, No. 4, pp. 22-23, 2007.

[18] Campbell, S. W., Galloway, A. M. and McPherson, N. A., 'Techno-economic evaluation of reducing shielding gas consumption in GMAW whilst maintaining weld quality', International Journal of Advanced Manufacturing Technology, Vol. 63, No. 69, pp. 975-985, 2012.

[19] Beyer, V., Campbell, S. W., Ramsey, G. M., Galloway, A. M., Moore, A. J. and McPherson, N. A., 'Systematic study of the effect of cross-drafts and nozzle diameter on shield gas coverage in MIG welding', Science and Technology of Welding and Joining, Vol. 18, No. 8, pp. 652-660, 2013. 
[20] Ramsey, G. M., Galloway, A. M., Campbell, S. W., McPherson, N. A. and Scanlon, T. J., 'A computational fluid dynamics analysis of the effect of side draughts and nozzle diameter on shielding gas coverage during gas metal arc welding', Journal of Materials Processing Technology, Vol. 212, No. 8, pp. 1694-1699, 2012.

[21] Campbell, S. W., Galloway, A. M., Ramsey, G. M. and McPherson, N. A., 'A computational fluid dynamic analysis of the effect of weld nozzle geometry changes on shielding gas coverage during gas metal arc welding', Journal of Manufacturing Science and Engineering, Vol. 135, No. 5, Article 051016, 2013.

[22] Campbell, S. W., Ley, F. L., Galloway, A. M. and McPherson, N. A., 'Artificial neural network optimization of shielding gas flow in gas metal arc welding subjected to cross drafts when using alternating shielding gases, Proceedings of the Institution of Mechanical Engineers, Part B: Journal of Engineering Manufacture, Vol. 229, No. 1, pp. 122-129, 2015.

[23] Masubuchi, K., 'Models of stresses and deformation due to welding - a review', JOM, Vol. 33, No. 12, pp. 19-23, 1981.

[24] Zhu, X. K. and Chao, Y. J., 'Effects of temperature-dependant material properties on welding simulation', Computers and Structures, Vol. 80, No. 11, pp. 967-976, 2002.

[25] Barclay, C. J., Campbell, S. W., Galloway, A. M. and McPherson, N. A., 'Artificial neural network prediction of weld distortion rectification using a travelling induction coil', International Journal of Advanced Manufacturing Technology, Vol. 68, No. 1- 4, pp. 127-140, 2013. 
[26] Mollicone, P., Camilleri, D., Gray, T. G. F. and Comlecki, T., 'Simple thermoelastic-plastic models for welding distortion simulation', Journal of Materials Processing Technology, Vol. 176, No. 1-3, pp. 77-86, 2006.

[27] McPherson, N. A., 'Thin plate distortion - the ongoing problem in shipbuilding', Journal of Ship Production, Vol. 23, No. 2, pp. 94-117, 2007.

[28] Camilleri, D., Comlecki, T. and Gray, T. G. F., 'Computational prediction of out-of-plane welding distortion and experimental investigation', Journal of Strain Analysis for Engineering Design, Vol. 40, No. 2, pp. 161-176, 2005.

[29] Armentani, E., Esposito, R. and Sepe, R., 'The effect of thermal properties and weld efficiency on residual stresses in welding', Journal of Achievements in Materials and Manufacturing Engineering, Vol. 20, No. 1-2, pp. 319-322, 2007.

[30] Michaleris, P., Feng, Z. and Campbell, G., 'Evaluation of 2D and 3D FEA models for predicting residual stresses and distortion', Approximate Methods in the Design and Analysis of Pressure Vessels and Piping Components, American Society of Mechanical Engineers, Pressure Vessels and Piping Division, Vol. 347, pp. 91102, 1997.

[31] Camilleri, D., Mollicone, P. and Gray T. G. F., 'Alternative simulation techniques for distortion of thin plate due to fillet-welded stiffeners', Modelling and Simulation in Materials Science and Engineering, Vol. 14, No. 8, pp. 1307-1327, 2006.

[32] Welding and brazing: ASM metals handbook, $8^{\text {th }}$ edition, Vol. 6, pp. 37-38 (ASM, Metals Park Ohio). 